\title{
STUDI PENURUNAN PRESSURE STEAM PADA AUXILIARY BOILER DI MV. SITU MAS YANG MEMPENGARUHI KINERJA MAIN ENGINE
}

\author{
Muhamad Rusdiantoro ${ }^{1}$, Eka Darmana ${ }^{1^{*}}$, Agus Saleh ${ }^{1}$ \\ ${ }^{1}$ Program Studi Teknika Politeknik Bumi Akpelni Semarang \\ Jl. Pawiyatan Luhur II/17, Bendan Duwur, Semarang. \\ *Email: darmanaeka@gmail.com
}

\begin{abstract}
Abstrak
Kasus menurunnya tekanan boiler terjadi di kapal MV. Situ Mas. Hal ini mempengarui kebutuhan steam untuk memanaskan HFO dan minyal lumas menjadi tidak terpenuhi. Tujuan dari penelitian ini untuk mengetahui penyebab menurunnya tekanan boiler dan cara mengatasinya. Penelitian berdasarkan studi kasus di MV. Situ Mas Metode pengumpulan data diperoleh dengan cara observasi langsung di tempat penelitian, diskusi maupun wawancara dengan crew kapal dan studi pustaka yang bersumber dari instruction manual maupun standard operasional prosedur. Dari data data tersebut kemudian dilakukan analisis dengan pendekatan kualitatif diskriptif. Hasil studi menunjukkan penurunan pressure steam pada auxiliary boiler di MV. Situ Mas disebabkan oleh kegagalan pembakaran akibat bahan bakar boiler jenis HFO yang tercampur air yang berawal dari minyak kotor yang berada didalam Fuel Oil Leak Tank di transfer ke Settling Tank. Hal ini akibat kekurangtepatan analisa pengambilan keputusan yang mengunakan kembali minyak dari fuel oil leak tank. Upaya mengatasi hal tersebut dengan memindah jenis bahan bakar dari HFO ke MDO dan di drain sisa air yang ada di pipa bahan bakar.
\end{abstract}

Kata kunci: kegagalan pembakaran boiler, penurunan tekanan boiler, fuel oil leak tank

\section{PENDAHULUAN}

Dengan semakin berkembangnya ilmu pengetahuan dan teknologi serta peningkatan sektor ekonomi banyak dipengaruhi oleh perkembangan dalam bidang pelayaran, maka banyak perusahaan yang menggunakan jasa angkutan laut dalam usahanya untuk memenuhi kebutuhan perusahaan tersebut, dimana angkutan laut adalah transportasi paling efisien dan mampu memuat banyak barang dan bisa menjangkau antar benua. Perusahaan pelayaran dituntut untuk bisa memberikan pelayanan yang optimal kepada pengguna jasa, seiring dengan besarnya persaingan usaha pelayaran. Upaya tersebut sudah diwujudkan dengan penggunaan teknologi pada kapal-kapal di perusahaan pelayaran. Dalam menunjang keselamatan pelayaran di laut perlu adanya alat penunjang atau alat bantu kapal yang sesuai, sehingga dalam pelayaran tidak mengalami suatu hambatan. Alat bantu diantaranya adalah boiler, dimana boiler ini harus dapat bekerja dengan baik dan tanpa hambatan maka boiler perlu dilakukan perawatan secara continue sehingga hal ini dapat mengurangi terjadinya kerusakan yang lebih parah, mengingat dalam penggantian sparepart saat ini dirasa sangat mahal sehingga dengan perawatan ini dapat mengurangi pengeluaran biaya perusahaan. Ketika melaksanakan observasi di MV. Situ Mas, berbagai permasalahan terjadi pada boiler Saacke tipe CBKG 1,8 - 8 bar, salah satunya adalah menurunnya pressure steam yang normalnya pada tekanan 6.0 - 6.5 bar dan memiliki maximal high pressure alarm 8.0 bar pada boiler. Dimana saat itu burner tidak dapat menyala sampai pressure menurun di 2 bar sedangkan alarm low pressure steam pada boiler 4.0 bar, sehingga harus segera di selesaikan permasalahan tersebut agar tidak mengganggu jalannya permesinan di atas kapal terutama pada Main Engine dan Auxiliary Engine yang membutuhan steam untuk memanaskan bahan bakar jenis Heavy Fuel Oil ( HFO).

\section{LANDASAN TEORI}

Menurut Victoria Handiyan (2017), Auxilary Boiler (ketel uap bantu) merupakan mesin yang digunakan untuk memproduksi uap bertekanan yang sangat dibutuhkan di kapal, diantaranya untuk pemanas bahan bakar, 
minyak lumas, dan pemanas air untuk akomodasi maupun permesinan. Jenis dari ketel uap ini ada dua yaitu ketel pipa air dan ketel pipa api.

Menurut Wida Yuliati (2017), Ketel uap bantu di kapal merupakan salah satu permesinan bantu yang memiliki peranan penting untuk menghasilkan uap panas yang berkualitas.

\section{Jenis Boiler berdasarkan pipa:}

\section{a. Ketel pipa api (fire tube boiler)}

Pada ketel pipa api seperti tampak pada Gambar 1 dan Gambar 2, gas panas melewati pipa-pipa dan air umpan ketel ada didalam shell untuk dirubah menjadi steam. Ketel pipa api biasanya digunakan untuk kapasitas steam yang relatif kecil dengan tekanan steam rendah dan sedang. Sebagai pedoman, ketel pipa api kompetitif untuk kecepatan steam sampai $14.000 \mathrm{~kg} / \mathrm{jam}$ dengan tekanan sampai $18 \mathrm{~kg} / \mathrm{cm} 2$. Ketel pipa api dapat menggunakan bahan bakar minyak, gas atau bahan bakar padat dalam operasi. Untuk alasan ekonomis, sebagian besar ketel pipa api dikonstruksi sebagai "paket" boiler (dirakit oleh pabrik) untuk semua bahan bakar.
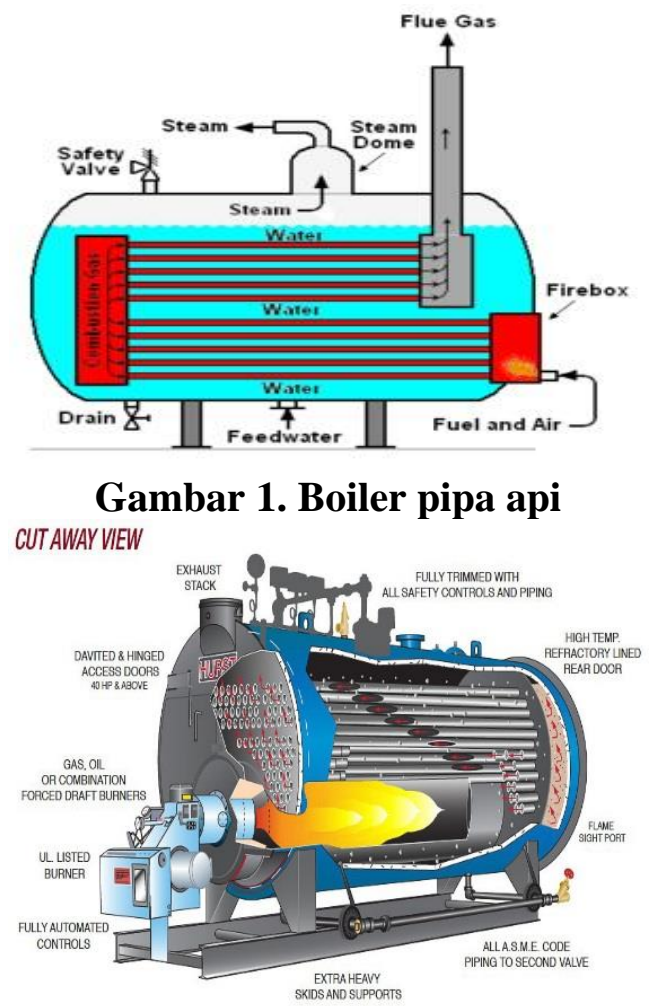

Gambar 2. Cut away view boiler pipa api b. Ketel pipa air (water tube boiler)

Pada ketel pipa air seperti tampak pada Gambar 3, air umpan boiler mengalir melalui pipa-pipa masuk kedalam drum. Air yang tersirkulasi dipanaskan oleh gas pembakaran membentuk steam pada daerah uap dalam drum. Ketel ini dipilih jika kebutuhan steam dan tekanan steam sangat tinggi seperti pada kasus ketel untuk pembangkit tenaga listrik.Untuk ketel pipa air yang menggunakan bahan bakar padat, tidak umum dirancang secara paket. Karakteristik ketel pipa air menurut Fadilah, Ridho, (2014) sebagai berikut:

- Force, induce dan balance draft membantu untuk meningkatkan effisiensi.

- Kurang toleran terhadap kualitas air yang dihasilkan dari pengolahan air.

- Memungkinkan untuk tingkat effisiensi panas yang lebih tinggi.

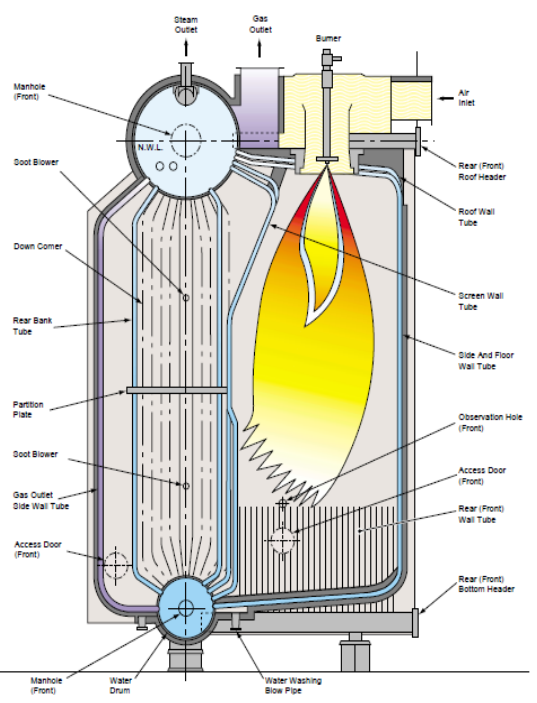

Gambar 3. Boiler pipa air Komponen Utama Boiler

Komponen utama Boiler antara lain

1. Steam,drum

2. Economizer

3. Superheater

4. Furnace

5. Burner

\section{Instrumen Penunjang Ketel Uap}

1. Manometer / Pressure Gauge

2. Safety valve

3. Thermometer

4. Water Level Gauge (Gelas Penduga) 
5. Blowdown Valve

6. Main Steam Valve

\section{Pembakaran}

Pembakaran yang baik adalah pembakaran yang melepaskan seluruh panas yang terbakar dalam bahan bakar. Agar mencapai pembakaran yang baik/sempurna, dilakukan pengontrolan 3T, yaitu:

a. Temperature yang mencukupi untuk proses penyalaan serta menjaga bahan bakar tetap terbakar.

b. Turbulence/percampuran antara oksigen dan bahan bakar yang homogen sesuai rasio pembakaran

c. Time/waktu

Artinya untuk mencapai fase pembakaran harus memenuhi waktu penyalaan (time to ignition) yang bergantung pada beberapa suhu ideal agar pembakaran dapat terjadi dan bagaimana kondisi aliran fluidanya. Semakin turbulen aliran fluida yang terjadi, maka proses perpindahan panas juga akan semakin cepat. Pada proses pembakaran dengan proses penyalaan api yang normal, dibutuhkan tiga komponen utama untuk tercapainya suatu fase pembakaran, yaitu panas, bahan bakar, dan oksigen. Ketiganya merupakan elemen-elemen yang harus ada untuk mewujudkan terjadinya proses pembakaran, sehingga jika salah satu elemen ditiadakan maka proses pembakaran yang ditandai dengan adanya nyala api dapat terhenti. Konsep inilah yang kemudian dijadikan dasar dalam mengontrol nyala api dari pembakaran. Tetapi, pada dasarnya keberadaan tiga elemen itu saja belum cukup untuk memenuhi syarat terjadinya nyala api pembakaran.

\section{Profil Pembakaran}

Mengetahui komposisi gas buang melalui pengukuran berguna untuk dapat mengerti dengan baik proses pembakaran yang terjadi dalam suatu boiler atau furnace.

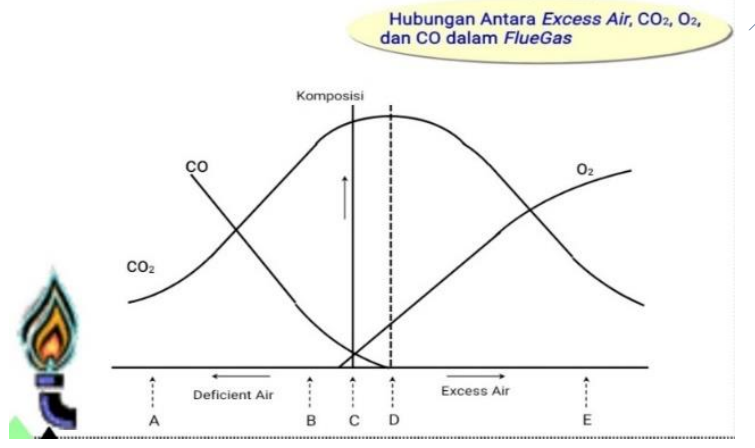

Gambar 4 Profil pembakaran

Pada Gambar 4 profil pembakaran bahan bakar hubungan antara udara berlebih dengan gas-gas hasil pembakaran dapat dijelaskan sebagai berikut:

1.Pada laju udara yang beada dibawah kebutuhan teoritis di titik A, semua karbon yang terkandung dalam bahan bakar tidak semua dapat diubah menjadi $\mathrm{CO} 2$, akantetapi lebih banyak kandungan $\mathrm{CO}$ yang dihasilkan.

2.Dengan menambahkan udara pada titik B, sebagian $\mathrm{CO}$ diubah menjadi $\mathrm{CO} 2$ dengan melepas lebih banyak panas. Kandungan $\mathrm{CO}$ dalam gas buang turun dratis dan $\mathrm{CO} 2$ menjadi naik.

3.Pada titik dimana udara stoikiometrik terpenuhi (titik C), semua kandungan karbon dapat seluruhnya diubah menjadi $\mathrm{CO}_{2}$ pada sistem ideal. Kondisi ini tidak pernah dapat dicapai.

4.terjadinya pembakaran normal (titik D) dapat dicapai dengan menambah sedikit udara diatas kebutuhan stoikiometrisnya (excess air) untuk mencapai pembakaran sempurna. Pada keadaan ini, $\mathrm{CO}_{2}$ pada angka maksimum, dan produksi $\mathrm{CO}$ pada angka minimum dalam gas buang.

5.Semakin banyak udara yang ditambahkan (titik E), maka nilai $\mathrm{CO} 2$ kembali turun karena bercampur dengan udara lebih (excess air). Udara lebih yang tinggi juga merugikan karena menurunkan temperature pembakaran dan menyerap panas berguna dalam gas buang.

\section{METODE PENELITIAN}

Penelitian dilakukan bedasarkan studi kasus yang terjadi pada boiler Saacke tipe 
$C B K G$ 1,8 - 8 bar di kapal MV. Situ Mas, yaitu menurunnya pressure steam dari kondisi normal 6.0 - 6.5 bar menjadi 2 bar sedangkan alarm low pressure steam pada boiler 4.0. Teknik pengumpulan data dilakukan dengan observasi langsung di kapal MV Situ Mas, wawancara dengan crew kapal bagian mesin dan studi Pustaka baik instruction manual, standard operasional prosedur (SOP) maupun literatur yang berhubungan dengan permasalahan tersebut. Jenis penelitian adalah kualitatif. Analisis data dilakukan dengan menelaah secara mendalam berdasarkan teori-teori yang yang ada kemudian disajikan secara diskriptif.

\section{HASIL DAN PEMBAHASAN}

Pada saat kapal sandar dipalabuhan Belawan, Sumatra Utara, Chief Engineer mengintruksikan kepada masinis 3 untuk memindah isi Fuel Oil Leak Tank ke Settling Tank HFO, dimana Fuel Oil Leak Tank berisi campuran tampungan lanjutan dari sludge tank purifier, buangan minyak kotor,air,dll. Dikarena Chief Engineer baru beberapa bulan dikapal dan mau mencoba memakai minyak yang terdapat di Fuel Oil Leak Tank. Sedangkan Chief Engineer yang lama tidak pernah memindah isi Fuel Leak Oil Tank ke Settling Tank, Karena isi dari Fuel Leak Oil Tank di pindah ke Dirty Oil Tank. Dirty Oil Tank di MV. Situ Mas kalau penuh ketika di pelabuhan Tanjung Priok, Jakarta akan di pindah ke truk tangki dari darat.

Indikator awal permasalah ketika purifier alarm terus menerus dan alarm tersebut membuat purifier berhenti otomatis. Ketika Purifier HFO di cek, ternyata terlalu banyak kotoran dan air yang ada pada bahan bakar HFO tersebut, yang melebihi batas kemampuan dari purifier untuk memisahkan air dan kotoran yang terkandung di bahan bakar HFO dari settling tank. Setelah beberapa jam kemudian boiler alarm low pressure steam. Pressure boiler terus menurun. Ketika dicek ternyata api burner tidak menyala sehingga di lakukan pengecekan pada burner, blower, fuel oil pump. Ketika filter bahan bakar boiler yang terdapat di HFO Fuel Oil Pump dibuka, keluar banyak air.

\section{Analisa Masalah}

Analisa masalah yang didapatkan dari hasil observasi selama kurun waktu 6 bulan di kapal. Adapun analisa masalah yang didapatkan dari hasil observasi yaitu penurunan pressure steam pada boiler Saacke di MV. Situ Mas dikarenakan gagal pembakaran dimana bahan bakar boiler tercampur air. Dengan bahan bakar bercampur air maka bahan bakar tidak dapat diatomisasi di nosel boiler pembakaran tidak berjalan sempurna (Raharjo,R.K 2017dan Taher,M. Usemahu, 2018), bahkan tidak dapat terjadi pembakaran.

Banyaknya kandungan air dimungkinkan terjadi karena penggunaan kembali minyak yang terdapat di fuel oil leak tank yang seharusnya tidak layak digunakan kembali. Keputusan berani yang diluar kebiasaan ini kemungkinan dilakukan dengan tujuan efisiensi penggunaan bahan bakar yang menjadi tuntutan oleh hampir semua perusahaan pelayaran. Akan tetapi resiko yang diperoleh akibat keputusan ini jauh lebih besar yaitu menghambat dan menurunkan kinerja boiler sehingga tujuan efisiensi bukannya tercapai justru malah sebaliknya. Kemampuan purifier dalam memisahkan air dan sludge ada batasnya, sehingga kalau minyak yang dimasukkan kedalam purifier sangat kotor bahkan isi dari fuel oil leat tank maka purifier tidak akan mampu memisahkan air maupun sludge didalam minyak. Akibatnya, minyak yang keluar dari purifier belum bersih dan banyak kandungan air didalamnya. Ketika minyak tersebut digunakan sebagai bahan bakar boiler maka akan terjadi kegagalan pembakaran. Kalau keadaan ini berlangsung beberapa waktu maka tekanan boiler akan terus menurun dan akibatnya kebutuhan steam tidak terpenuhi. Hal ini berdampak pada terperatur HFO yang dapat dimungkinkan turun dan dapat menghambat atau menurunkan kinerja dari main engine maupun auxiliary engine. 
Kalau efisiensi penggunaan bakar dengan metode seperti ini maka perlu dikaji ulang dampak maupun akibatnya, baik terhadap boiler maupun rentetannya dengan permesinan yang lain seperti main engine maupun auxiliary engine.

Penurunan tekanan boiler bukan hanya terjadi akibat standard operasional prosedur (SOP) yang tidak dipatuhi akan tetapi kekurangtepatan analisa dalam pengambilan keputusan juga sangat berpengaruh. Artinya sumber daya manusia dapat menjadi tolak ukur.

\section{Pemecahan Masalah}

Ketika masinis mengetahui penyebab api burner tidak menyala disebabkan bahan bakar yang tercampur oleh air, dimana pada saat itu jenis bahan bakar yang digunakan adalah HFO maka dilakukan pemindahan jenis bahan bakar ke MDO. Akan tetapi sisa bahan bahan bakar tercampur air harus di hilangkan dengan cara di drain dari pipa bahan bakar sebelum burner. Awal penyalaan burner terasa susah karena masih terdapat kandungan air, dengan menambah derajat handle blower dan bukaan valve bahan bakar sehingga perlahan api bisa nyala walaupun masih berwarna kuning kebiruan apinya. Dikondisi normal, api boiler di MV. Situ Mas berwarna biru. Dengan berjalannya waktu sisa air yang terdapat pada system pipa bahan bakar boiler tidak ada, nyala api burner kembali normal berwarna biru. Sedangkan bahan bakar HFO yang terdapat di Settling Tank dan Service Tank di Drain lewat valve drain tank sampai air sudah tidak ada. Dan kemudian purifier HFO dijalankan kembali tunggu sekitar kurang lebih 1 jam purifier HFO running tidak terjadi alarm lagi, Handle bahan bakar boiler yang tadi memakai jenis MDO di kembalikan ke pemakaian bahan bakar jenis HFO.

\section{KESIMPULAN}

kesimpulan dan saran yang tersirat berdasarkan uraian pembahasanpembahasan masalah diatas adalah:

1. Bahan bakar HFO boiler tercampur dengan air dikarenakan kurang optimalnya purifier HFO yang tidak sanggup membersihkan Minyak bahan bakar (Heavy Fuel Oil) yang mengandung campuran air dan kotoran lainnya disebabkan melebihi batas kapasitas kemampuan purifier tersebut.

2. Kesalahan analisis dampak dan akibat dari keputusan Chief Engineer. Perlunya menganalisis lebih pada saat melakukan sesuatu tindakkan/ keputusan dengan melihat dampak dan akibatnya kedepan. Ini terkait dengan sumber daya manusia.

3. Penanganan masalah yang terjadi terhadap auxiliary boiler harus segera di selesaikan agar tidak menggangu jalan nya permesinan diatas kapal.

4. Bahan bakar HFO untuk boiler yang tercampur oleh air, diatasi dengan mengganti menggunakan bahan bakar jenis MDO sembari mendrain bahan bakar sisa yang tercampur air pada boiler.

\section{DAFTAR PUSTAKA}

Fadilah, Ridho, 2014, Makalah Ketel Uap, https://www.academia.edu, diakses tanggal 16 Agustus 2020 jam 16.15 WIB.

Handiyan, Victoria, 2017, Analisis Penyebab Kegagalan Pembakaran pada Burner Boiler di Atas Kapal, Jurnal Dinamika Bahari, Vol.8, No.1, pp. 1844-1854.

Raharjo, R.K, 2017, Prioritas Pencegahan Kegagalan Pembakaran pada Boiler di MV. Brussels Bridge, Prosiding Seminar Bidang Teknika Pelayaran. Vol. 7, No.2, pp. 1-9.

Taher,M. Usemahu, 2018, Optimalisasi Pengoperasian Boiler dalam Memproduksi Uap untuk Menunjang Pengoperasian Kapal MV. Sinar Kutai, METEOR STIP Marunda, Vol. 11, No.2, pp. 16-21.

Yulianti, Wida. 2017, Kurang Optimalnya Pembakaran Pada Auxiliary Boiler Yang Menghambat Proses Bongkar Muat di MT. Enduro, Jurnal Dinamika Bahari, Vol.8, No.1, pp. 1930-1944 